\title{
Study on the Physical Education Supervision Systems at Home and Abroad
}

\author{
Yangjing, Gouming \\ Southwest University of Political Science and Law, Chongqing, China
}

\begin{abstract}
PE) supervision systems of schools in China and other developed countries is meaningful for the location of issues existing in China's system, which can not only help to promote the PE supervision level of Chinese schools, but also contribute to timely find out the substantial distance between the PE supervision systems at home and abroad, so as to enable the prompt adjustment of direction and error correction, and facilitate the formation of a scientific and complete theory and practice system of PE supervision for Chinese schools.
\end{abstract}

KEYWORD: PE; education supervision; comparative study

\section{FOREWORD}

Since the beginning of the century, Chinese authorities have clearly recognized the continuous declination of students' physique might cause some problems. In 2006, the Ministry of Education, the General Administration of Sport, and the Central Committee of the Communist Young League of China jointly issued the Decision on the Development of Sunshine Physical Exercise among Hundreds of Millions of Students all over the Country (hereinafter referred to as the "Sunshine PE"), and in 2007, the Central Committee of the Communist Party of China and the State Council jointly issued the Opinions on Enhancing Physical Education among Teenagers to Improve Physical Healthy of Teenagers (hereinafter referred to as the "Document No.7), etc. As a researcher, the author feels both "delighted" and "worried". I am worried that the "structural problem" may lead to failure to implement the document spirit. Via historical analysis on the PE supervision of Chinese schools, the paper aims to locate the current situation of the PE supervision of Chinese schools, find out and summarize the excellent school running experience, and look out the problems existing in the supervision objects. Meanwhile, it also aims to promote the PE working efficiency and quality of schools through the resolution of these problems.

\section{OBJECTS AND METHODS OF SUDY}

\subsection{Objects of study:}

The PE supervision methods of China, England, USA, and Russia, etc.

\subsection{Methods of study:}

Literature data method, questionnaire method, and mathematical statistics method

\section{CONCLUSIONS AND SUGGESTIONS OF STUDY}

3.1 The PE supervision of schools falls under the category of education supervision. Since 1990s, developed countries such as the US, England, Canada, Australia, Spain, New Zealand, Sweden, Denmark, Netherlands, and Israel, etc. have increasingly attempted to establish "educational accountability system" to ensure the efficiency of financial investment and administrative service of education, and avoid problems of "low efficiency" and "poor education performance". Therefore, the pursuit of "fairness and excellence" has become the development tendency of education in the world today. China has explicitly put forward the requirement on enhancing the supervisory inspection of PE work of schools in the PE reform plan, and set up the specific targets such as establishing specific supervision system for PE work of schools, revising the PE Supervision Assessment Measures for 
Elementary and Secondary Schools (Trial), etc. During the course of PE reform of schools, the study of coincide with the right time, and it is wished that the results can offer some reference basis for the relevant authorities.

3.2 In the $17^{\text {th }}$ and $18^{\text {th }}$ centuries, many PE activities similar to the forms of those today have appeared in regions like Europe. For example, measuring and recording performance in $\mathrm{PE}$ activities, and retaining the records, etc. The concepts of fairness and openness have led to worldwide revolution in Europe and America, etc. Meanwhile, it had further boosted the development of modern PE and emphasized the role of PE in education. Moreover, naturalistic educators have also conducted experiments on modern education and PE, which has successfully led to the establishment of PE in schools. All of these have created pre-conditions for the wide implementation of modern PE. The $19^{\text {th }}$ century had also been the establishment period of school PE systems and regulations in various modern countries, during which, PE had been vigorously grown, and European and North American regions had started to focus on PE activities and health, particularly health had been highly emphasized. Meanwhile, bodybuilding, gymnastics, and outdoor exercises had been underlined by the public. Some new sport forms (basketball, volleyball, etc.) appeared in succession, and many countries started to build PE system (including school PE, PE management, and professional PE, etc.).

In 1805, Denmark government ordered the secondary schools to set up "gym class". In 1814, it followed to issue an order which explicitly regulated that the requirements for the employment of $\mathrm{PE}$ teachers in elementary schools and the playground equipment, and listed "gym class" the content of general education. After 1820, Sweden government issued the statute to implement $\mathrm{PE}$ in secondary school for males, and set up PE supervisor in many cities. During 1842-1894, Germany issued 6 orders in succession to list gym training the constituent part of male education and the compulsory class of female schools, which made German schools all listed PE the compulsory course. In 1872, 1880, 1887, and 1905, French government stipulated gym a formal curriculum of schools in the manner of laws in succession. After that, PE departments were set up for male students first, followed by female students. Lastly, private schools and church affiliated schools also keep up with the trend. In 1872, Japan also listed gym the teaching content of schools; in 1913, Japanese Ministry of Education issued the "Details on Teaching Gym in Schools" to specifically stipulate the PE teaching material contents, teaching material allocation, extracurricular activities and precautions of all schools. In 1885, England also regulated PE the compulsory course of elementary schools, while the PE for colleges and middle schools had not been uniformly regulated until 1930s. In 1886, California issued the School Act, which expressly stipulated to implement "standard physical training" to students. While levels of public schools in the US had not listed PE the regular course until the beginning of the $20^{\text {th }}$ century. During the first half of the $20^{\text {th }}$ century, sport events abroad had achieved rapid growth, and some countries in Europe and America, for example, had made reforms of various degrees on PE, and the Soviet Union also established the new state PE system. As of 1990s, developed countries such as the US, England, Canada, Australia, Spain, Sweden, Denmark, Netherland, and Israel, etc. had increasingly established "educational accountability system" to enhance the effect of evaluation, supervision and guiding of educational supervision on the educational quality of schools. W. F. Lloyd believed that, "I think supervision system is as important as training system. In the area of education, there shall be a pair of vigilant eyes everywhere. I think such a supervision system for all schools in the country will be good for the whole society, and will help teachers to expand the improvement experience and provide information, which will boost and guide them to make further efforts.

3.3 England was the first western country building the modern educational supervision system, which has experience over 160 years since its first appointment of royal education supervisor in 1839, and has now formed a relatively stable and mature natural educational supervision network with both central and local levels. It has thoroughly influenced on the education of the country. Article IX of the Education Act stipulated the keys for the supervision: (1) the education quality of the school; (2) level and performance of the students; (3) development of students in terms of spirits, morality, society and culture, etc.; (4) educational resources and equipment; (5) and leading and managing English supervisory contents, which have offered many references for China to set up indicator system. However, we often neglect the supervision of (3), which also highlights the lack of completeness and delicateness of Chinese supervisory assessment indicator system comparing with that of some countries abroad.

3.4 The US has set remarkably detailed supervisory indicators of $\mathrm{PE}$, and specific regulations have been made against the degree of each grade. Educational supervision has many varieties and high degree of specialization, which emphasizes the supervision of schools and local 
education authorities; and focuses on utilizing market mechanisms such as bidding to subcontract the supervision projects to professional supervision assessment agencies for the development of specific supervision works, which has promoted the objectivity, efficiency and specialty of educational supervision; and establishes systematical supervision laws to regulations for sticking to supervision according to laws. This is also a goal for $\mathrm{PE}$ supervision reform of Chinese schools to strive for.

3.5 The government of Russian Federation expressly pointed out in the general principles of the Regulations on the Federal Education and Scientific Supervision Bureau issued in June 2004 that, the Federal Education and Scientific Supervision Bureau is a federal executive agency for implementing inspection and supervision roles, whose major working target is guaranteeing the monitoring on the implementation of federal laws by educational authorities, the academic activities in the educational system, and the evaluation activities for educational and scientific workers. Therefore, basically speaking, the educational and supervisory system of Russia is a kind of restrictive and monitoring supervision system.

\section{BRIEF SUMMARY}

The relevant theoretical study results of the academic circles is helpful for enhancing the awareness of the public on the PE supervision of schools, and offering valuable enlightenment for the study, which have left some issues to be further resolved:

Firstly, developed countries have relatively mature systems in terms of theoretical and practical fields, which have laid reference for the $\mathrm{PE}$ supervision of Chinese schools in respect of legislation, systematization, scientization and the specific operation. Due to the differences of national conditions, we must establish the theoretical and practical systems for the educational supervision and school PE supervision with Chinese characteristics according to Chinese own national conditions.
Secondly, as seen from the research status of supervision: in respect of the research perspectives, mostly researches have been still resting on the researches on macroscopic level. China is still weak in the systematic research on the PE supervision system of schools; in respect of research contents, most of the researches have been centering on that of a specific point, level or a field, but the systematical and completed researches are lacked.

Thirdly, as seen from the survey situation, the shortcomings in respect of theoretical researches on the PE supervision of schools have caused the fact that the specific supervision indicator system of school PE has fallen severely behind the practices. Meanwhile, the evaluation standards are mainly centering on the two dimensions of pass rate of PE course and physical health rate. In respect of the evaluation method, materials are mainly emphasized, thus the objectivity of the assessment is hard to be assured. As seen from the assessment indicator design, the PE supervision of schools is still focusing on "educational supervision" instead of "administration supervision", which indicates an urgent demand to enhance the relevant theoretical researches.

In view of this, we shall conduct thorough and systematical comparison analysis on the current situation of China's school PE supervision, so as to find out the existing problems and the corresponding solutions. This will not only promote the specific PE supervision level of Chinese schools, but also help us to timely find out the substantive distances with the PE supervision of foreign countries, so as to enable the prompt adjustment of direction and error correction, and facilitate the formation of a scientific and complete theory and practice system of PE supervision for Chinese schools.

\section{REFERENCES}

[1] Wang Shuyan. Empirical Research on the PE Supervision and Assessment Indicator System of Schools - A Case Study on Heilongjiang Ordinary Secondary Schools. Fujian Normal University, June 2009.

[2] Deng Hanchao, Qin Chunlin. Sport Management. Peoples Sports Publishing House, Beijing, Jan. 1999.

[3] Liu Bing. Course Book of Sport Management (New Edition). Fudan University Press. Apr. 2004. P134 